Provided for non-commercial research and education use. Not for reproduction, distribution or commercial use.

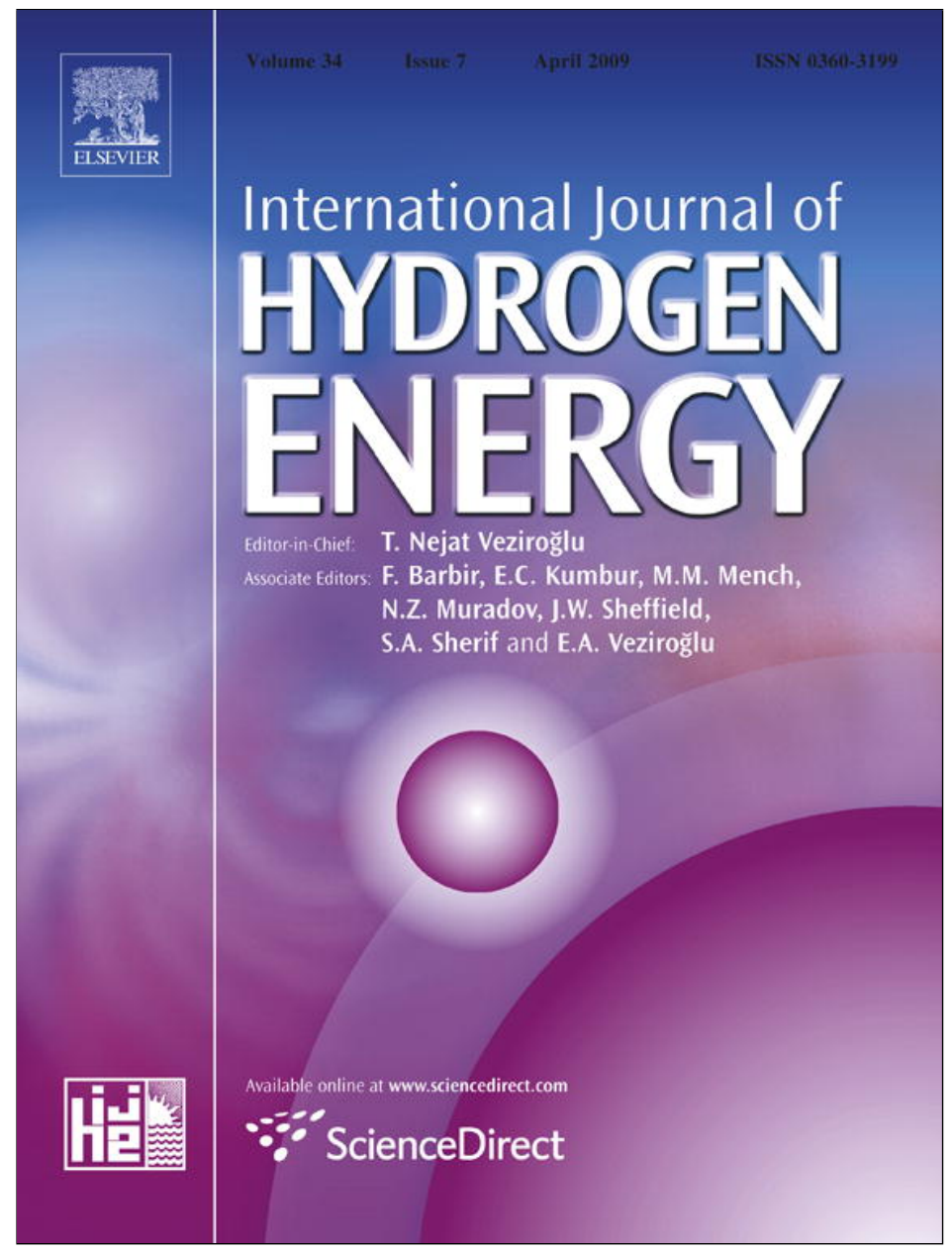

This article appeared in a journal published by Elsevier. The attached copy is furnished to the author for internal non-commercial research and education use, including for instruction at the authors institution and sharing with colleagues.

Other uses, including reproduction and distribution, or selling or licensing copies, or posting to personal, institutional or third party websites are prohibited.

In most cases authors are permitted to post their version of the article (e.g. in Word or Tex form) to their personal website or institutional repository. Authors requiring further information regarding Elsevier's archiving and manuscript policies are encouraged to visit:

http://www.elsevier.com/copyright 


\title{
New nano-structured and interactive supported composite electrocatalysts for hydrogen evolution with partially replaced platinum loading
}

\author{
Perica Paunovića,*, Ivan Radev ${ }^{b}$, Aleksandar T. Dimitrov ${ }^{a}$, Orce Popouskic, \\ Elefteria Lefteroua ${ }^{b}$, Evelina Slaucheva ${ }^{b}$, Suetomir Hadži Jordanov ${ }^{a}$
}

${ }^{a}$ Faculty of Technology and Metallurgy, University "Sts. Cyril and Methodius", Ruger Bošković Str., 16, 1000 Skopje, Republic of Macedonia

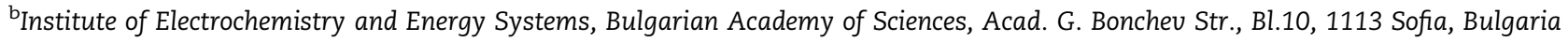
${ }^{c}$ Military Academy, Mihajlo Apostolski Str., b.b., 1000 Skopje, Republic of Macedonia

\section{A R T I C L E I N F O}

\section{Article history:}

Received 17 November 2008

Received in revised form

9 January 2009

Accepted 10 January 2009

Available online 24 February 2009

\section{Keywords:}

Hypo-hyper d-electrocatalysts Hydrogen evolution

Reduced platinum

Membrane electrode assembly (MEA)

\begin{abstract}
A B S T R A C T
This work is concerned with preparation and characterization of nano-structured composite electrocatalytic material for hydrogen evolution based on CoPt hyper d-metallic phase and anatase $\left(\mathrm{TiO}_{2}\right)$ hypo d-phase, both deposited on multiwalled carbon nanotubes (MWCNTs) as a carbon substrate. The main goal is partially or completely to replace Pt as the electrocatalytic material. Four electrocatalytic systems were prepared with common composition $10 \% \mathrm{Me}+18 \% \mathrm{TiO}_{2}+$ MWCNTs, where $\mathrm{Me}=\mathrm{Co}$, CoPt (4:1, wt. ratio), CoPt (1:1, wt. ratio) and Pt. The structural changes and their influence on electrocatalytic activity were studied by means of XRD, TEM, SEM and FTIR. The electrocatalytic activity was assessed in aqueous alkaline and polymer acidic electrolytes by means of steady-state galvanostatic method. It was found that Co strongly affects the platinum particle size. The addition of Co reduces platinum particle's size from $11 \mathrm{~nm}$ (in pure Pt metallic system) to $4 \mathrm{~nm}$ (in both systems $4: 1$ and 1:1), i.e. almost by 3 times. The corresponding increase of the surface area and the number of the active catalytic centres improves the efficiency, despite the fact that the amount of used platinum was decreased up to 5 times. The catalyst based on CoPt (1:1) performed the best, while the activity of the pure platinum and CoPt (4:1) systems were very close. Generally, the studied electrocatalysts have shown good and stable performances for hydrogen evolution in PEM electrochemical cell. The influence of the hydrogen electrodes under investigation on the water electrolysis efficiency at current density of $0.3 \mathrm{~A} \mathrm{~cm}^{-2}$ was assessed, using previous data oxygen evolution on $\mathrm{IrO}_{x}$ electrode. Related to the performances of commercial Pt (ELAT) electrode, when hydrogen electrodes with the prepared mixed electrocatalysts were used, the water electrolysis efficiency was only $5 \%$ lower for CoPt (1:1), nearly 10\% lower for CoPt (4:1) and 13\% lower in the case of pure Co-based electrocatalyst.
\end{abstract}

๑ 2009 International Association for Hydrogen Energy. Published by Elsevier Ltd. All rights reserved.

\footnotetext{
* Corresponding author. Tel./fax: +389 23064392.

E-mail address: pericap@tmf.ukim.edu.mk (P. Paunović). 0360-3199/\$ - see front matter @ 2009 International Association for Hydrogen Energy. Published by Elsevier Ltd. All rights reserved. doi:10.1016/j.ijhydene.2009.01.024
} 


\section{Introduction}

The membrane electrode assembly (MEA) as a structure of cathode-membrane (solid electrolyte)-anode, can be considered as a driving force of modern fuel cells/water electrolysers. It is a meeting place of three phases (ionic conductor-electronic conductor-gas) where electrochemical reactions occur. So, the power efficiency of MEA depends on the material characteristics of both the electrodes (electronic conductors) and membranes (ionic conductors) as well as on the architecture of the triple phase boundary [1-9].

Innovation of non-platinum electrode materials for water electrolysers/fuel cells is a very important issue within the hydrogen economy, which is considered as the most perspective energy system in the future. The commercial application of the still leading electrode material - Pt is limited due to its high cost and low abundance. About $50 \%$ of the modern fuel cell cost is attributed to MEA in which Pt cost is more than $70 \%[10,11]$. On the other hand, according to some analysis [11-13], the present resources of Pt are enough to cover only $20 \%$ of the automotive industry needs. What about the remaining $80 \%$ ? What about the future electricity needs that are considerably higher than in the automotive industry?

Considering the above facts, the main goal of the modern electrocatalysis and material science employed in hydrogen economy, is to reduce or even to replace platinum in the MEA, keeping the same level of efficiency. There are two main approaches to achieve this: i) exploration of synergetic mixture of non-platinum electrocatalytic materials (ex., Jakšić hypo-hyper d-concept [14-16]) and ii) replacement of the traditional carbon support materials (ex., Vulcan XC-72) with carbon nanotubes [17-19].

The previous works of the present authors were concerned with production and characterization of so-called hypo-hyper d-electrocatalysts, containing $10 \% \mathrm{Me}+18 \% \mathrm{TiO}_{2}+$ carbon substrate [20-22]. Different metallic phases were studied such as $\mathrm{Ni}$, Co or CoNi, deposited on both traditional Vulcan XC-72 and multiwalled carbon nanotubes (MWCNTs). Hypohyper d-interaction between metallic phase and $\mathrm{TiO}_{2}$ (anatase) contributes to the intrinsic activity of the electrocatalyst. The better electrical and surface characteristics of MWCNTs provide considerable increase of the electrocatalysts' real surface area as well as more uniform dispersion of the active catalytic centres over the whole catalyst's surface. The best activities were achieved when hypo-hyper d-mixture $\mathrm{Co}-\mathrm{TiO}_{2}$ was deposited on activated/purified MWCNTs in nitric acid [23], approaching performances of corresponding traditional Pt electrocatalyst deposited on Vulcan XC-72. The performance of these electrocatalysts in proton exchange membrane (PEM) electrolyte at lower cathodic overpotentials was not so impressing, while at higher overpotentials their activity approaches the performance of a traditional Pt catalyst [24].

The subject of this work is to study the catalytic activity of hypo-hyper d-Co-Pt based electrocatalysts deposited on activated/purified MWCNTs as carbon support. Hydrogen evolution reaction (HER) was tested in alkaline water electrolyser as well as in the so-called EasyTest Cell (ETC) using a proton exchange membrane as an electrolyte [25].

\section{Experimental}

The investigated electrocatalysts contain $10 \mathrm{wt} . \%$ metallic phase (Co, CoPt or Pt, see Table 1), 18 wt. $\% \mathrm{TiO}_{2}$ as anatase and activated/purified MWCNTs. As precursors for hyper d-metallic and hypo d-oxide phase orgnometallics were used (Me-2,4-pentanedionate, $\mathrm{Me}=\mathrm{Co}$ or Pt, Alfa Aesar, Johnson Matthey, GmbH and Ti-isopropoxide, Aldrich, 97\%). Multiwalled carbon nanotubes (MWCNTs, Guangzhou Yorkpoint Energy Company, China) were used as carbon substrate. The catalysts were produced by a sol-gel procedure [20]. In the first stage, in order to deposit $\mathrm{TiO}_{2}$ onto carbon substrate, Tiisopropoxide (Aldrich, 97\%) was added into dispersed activated MWCNTs in anhydrous ethanol. To provide hydrolysis to $\mathrm{Ti}(\mathrm{OH})_{4}$, small amount of $1 \mathrm{M} \mathrm{HNO}_{3}$ was added. This mixture was evaporated at $60^{\circ} \mathrm{C}$ with continuous intensive stirring until fine nano-structured powder of catalyst support was obtained. Further, individual or mixed Me-2,4-pentanedionate was dissolved in anhydrous ethanol. This solution was added into dispersed catalyst support in anhydrous ethanol. The evaporation was carried out under the same conditions as above. The aim of this operation is to graft the metal-hyper d-phase onto catalyst support. To decompose both $\mathrm{Ti}(\mathrm{OH})_{4}$ to $\mathrm{TiO}_{2}$ and the residual amount of oraganometallics, the powder was heated for $2 \mathrm{~h}$ at $480^{\circ} \mathrm{C}$ in the atmosphere of $\mathrm{H}_{2}+\mathrm{N}_{2}$. Before the sol-gel preparation of the catalysts, activation/purification of the as-prepared MWCNTs in $28 \mathrm{wt} . \% \mathrm{HNO}_{3}$ was performed.

Firstly, the produced electrocatalysts were electrochemically tested for hydrogen evolution in alkaline electrochemical cell. Porous electrodes aimed for three phase operation in alkaline cell (solid electrode, liquid electrolyte and $\mathrm{H}_{2}$ gas as a product) were prepared. They consist of two layers: i) a catalytic layer facing the electrolyte, covered by catalyst with low amount of PTFE and ii) a gas-diffusion layer facing the gas side, consisting of Vulcan XC-72 bonded with PTFE. The electrode preparation procedure is described elsewhere [26]. Electrochemical investigations were performed using AMEL equipment (Function Generator AMEL 568, Potentiostate/Galvanostate 2053 and software package SOFTASSIST 2.0). The counter electrode was a platinum wire and the reference electrode $-\mathrm{Hg} / \mathrm{HgO}$. The electrolyte was an aqueous solution of 3.5 $\mathrm{M} \mathrm{KOH}$ (p.a., Merck) at room temperature.

The structural characteristics of the studied electrocatalysts were observed by means of XRD, TEM, SEM and FTIR

\section{Table 1 - Composition of the studied electrocatalysts.}

\begin{tabular}{llcl}
$\begin{array}{l}\text { Sample } \\
\text { no. }\end{array}$ & $\begin{array}{c}\text { Hyper-metal d- } \\
\text { phase (10\%) }\end{array}$ & $\begin{array}{c}\text { Hypo-oxide d- } \\
\text { phase (18\%) }\end{array}$ & $\begin{array}{c}\text { Carbon } \\
\text { substrate } \\
(72 \%)\end{array}$ \\
\hline 1 & Co & $\mathrm{TiO}_{2}$ & MWCNTs \\
2 & CoPt (4:1, wt. ratio) & $\mathrm{TiO}_{2}$ & MWCNTs \\
3 & CoPt (1:1, wt. ratio) & $\mathrm{TiO}_{2}$ & MWCNTs \\
4 & Pt & $\mathrm{TiO}_{2}$ & MWCNTs \\
$5^{\text {a }}$ & Pt & - & Vulcan XC-72
\end{tabular}

a In this sample there is no $\mathrm{TiO}_{2}$, so the content of Vulcan XC-72 is $90 \%$. 
analysis. XRD was employed in order to identify the present phases in the catalysts and to determine their crystallite size. XRD measurement was carried out by X-ray diffractometer Philips APD 15, with $\mathrm{Cu} \mathrm{K} \alpha$ radiation. The crystallite size was calculated using the Scherrer equation, $D=k \lambda / \beta \cos \theta$, where $D$ is the crystallite size, $k=0.9$ is a constant, $\lambda$ is the X-ray wavelength, $\theta$ is the diffraction angle and $\beta$ is the full width at half maximum (FWHM) of the diffraction peak at $\theta$ [27]. The morphology and the particle size of the electrocatalysts were investigated by scanning (SEM) and transmission (TEM) electron microscopy. Transmission electron microscope JEOL JEM - 200 CX was used in scanning and transmission regime. Infrared spectroscopy was employed to determine the strength of hypo-hyper d-interaction $\left(\mathrm{Me}-\mathrm{TiO}_{2}\right)$. FTIR spectra were recorded using $\mathrm{KBr}$ pellets at room temperature with Perkin-Elmer System 2000 interferometer.

Further, performances for hydrogen evolution reaction of the prepared electrocatalysts were tested in ETC. The ETC design and its operational principle is described elsewhere [25]. MEA consisted of working electrode containing the studied electrocatalysts and a counter electrode of the commercial Pt ELAT, both grafted on a commercial Nafion 117 membrane (Alfa Aesar). A small piece of Pt electrode ELAT (ca. $0.1 \mathrm{~cm}^{2}$ ) was used as a reference hydrogen electrode (RHE). All electrochemical measurements in ETC were carried out with a Galvanostat/Potentiosat POS 2, Bank Electronik, and CPCDA software, at $80^{\circ} \mathrm{C}$ and relative humidity (RH) of $100 \%$.

The MEAs under study were prepared by hot pressing of catalyzed gas-diffusion layers on both sides of the polymer membrane. The proton conductivity in the catalytic layers and the attachment of the prepared electrodes to the PEM were ensured by an optimized amount $\left(15 \mu \mathrm{cm}^{-2}\right)$ of $5 \mathrm{wt}$.\% Nafion solution (Alfa Aesar). Immediately, a hot pressing was performed gradually increasing the temperature and pressure starting at $50{ }^{\circ} \mathrm{C}$ and $50 \mathrm{~kg} \mathrm{~cm}^{-2}$ and ending at $120^{\circ} \mathrm{C}$ and $120 \mathrm{~kg} \mathrm{~cm}^{-2}$. The amount of the metallic phase in the electrodes under study was $1 \mathrm{mg} \mathrm{cm}^{-2}$. All electrode potentials presented were measured versus RHE at the given testing conditions. For comparison, the polarisation curves of a commercial ELAT electrode (ELAT (R) V.21, Lot \# MB030105-1, Pt loading $0.5 \mathrm{mg} \mathrm{cm}^{-2}$, E-TEK) were also recorded.

\section{Results and discussions}

\subsection{Structural characteristics}

In Fig. 1 are shown XRD spectra of the studied electrocatalysts. In all samples $\mathrm{TiO}_{2}$ was detected as crystalline anatase [28] with crystallite size about $4 \mathrm{~nm}$. Characteristic peaks of Co cannot be seen due to its amorphous character and very small particles [20,21]. Only in spectrum 1 (sample with pure Co as metallic phase) a very weak peak was indicated at $2 \theta=44.22^{\circ}$, corresponding to (111) reflection of cubic Co [29]. Within spectrum 4 (sample with pure Pt as metallic phase) wellpronounced peaks of crystalline Pt can be seen [30], with crystallite size about $11 \mathrm{~nm}$. The corresponding Pt peaks in spectra 2 and 3 (samples with mixed Co and Pt metallic phases) are considerably weaker. The position of the Pt peak is the same as that in the pure Pt metallic system (sample 4)

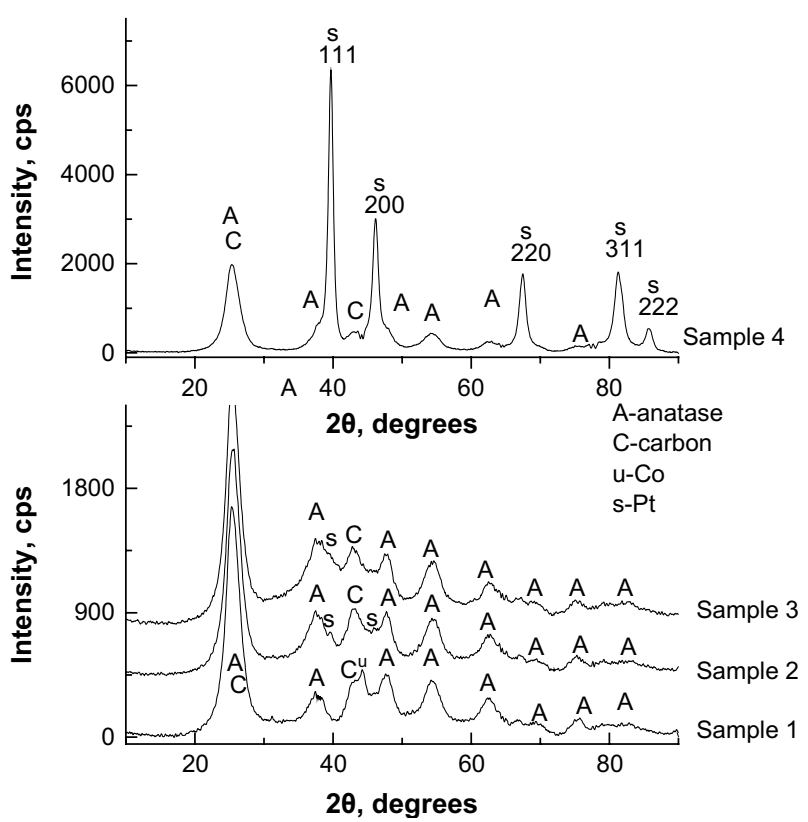

Fig. 1 - XRD analysis of the studied electrocatalysts.

suggesting that in the mixed CoPt systems there is no new CoPt intermetallic phase, but only a mixture of Co and Pt particles exists. This is confirmed by the fact that the Co phase spectrum of the bimetallic catalysts is the same as in the pure Co metallic system (sample 1).

In order to estimate particle size as well as to observe the dispersion of catalyst's components over the surface, TEM analysis was performed (Fig. 2). There is a strong correlation between XRD and TEM analyses related to the crystallite size and the particle size. The black spots represent the metallic phase particles over the catalyst's surface. In the case of pure Pt (Fig. 2b) the diameter of these black spots is $10-12 \mathrm{~nm}$. The same value was determined by XRD analysis for the crystallite size. The black spots in the catalysts with mixed metallic phase are much smaller or very poorly visible (Fig. $2 \mathrm{c}$ and d) and their size is not greater than $4 \mathrm{~nm}$. The diameter of the activated MWCNTs is about 8-10 $\mathrm{nm}$. In all samples, the components are uniformly well dispersed over the catalyst's surface.

By both analyses it was shown that Pt particles in the presence of Co are considerably smaller (about 3-4 times). Thus, cobalt can be considered as a promoter for reduction of the platinum particle size which was observed also by other authors [31-33]. Smaller particles mean higher surface area of the metallic phase and greater number of active catalytic centres which are more uniformly dispersed over the catalyst's surface. This is favourable for the electrocatalytic activity toward hydrogen evolution.

The results of SEM analysis are shown in Fig. 3. The studied electrocatalysts show intertwined thread-like morphology, as a result of the presence of MWCNTs. This morphology is more appropriate than that of electrocatalysts deposited on carbon blacks $[20,21]$. In this case the catalyst's components are grouped into smaller clusters, there are more holes between them, which leads to better inter-particle porosity of the catalysts. Due to the intrinsic geometric shape of MWCNTs (empty cylinders ordered one over the other), they 

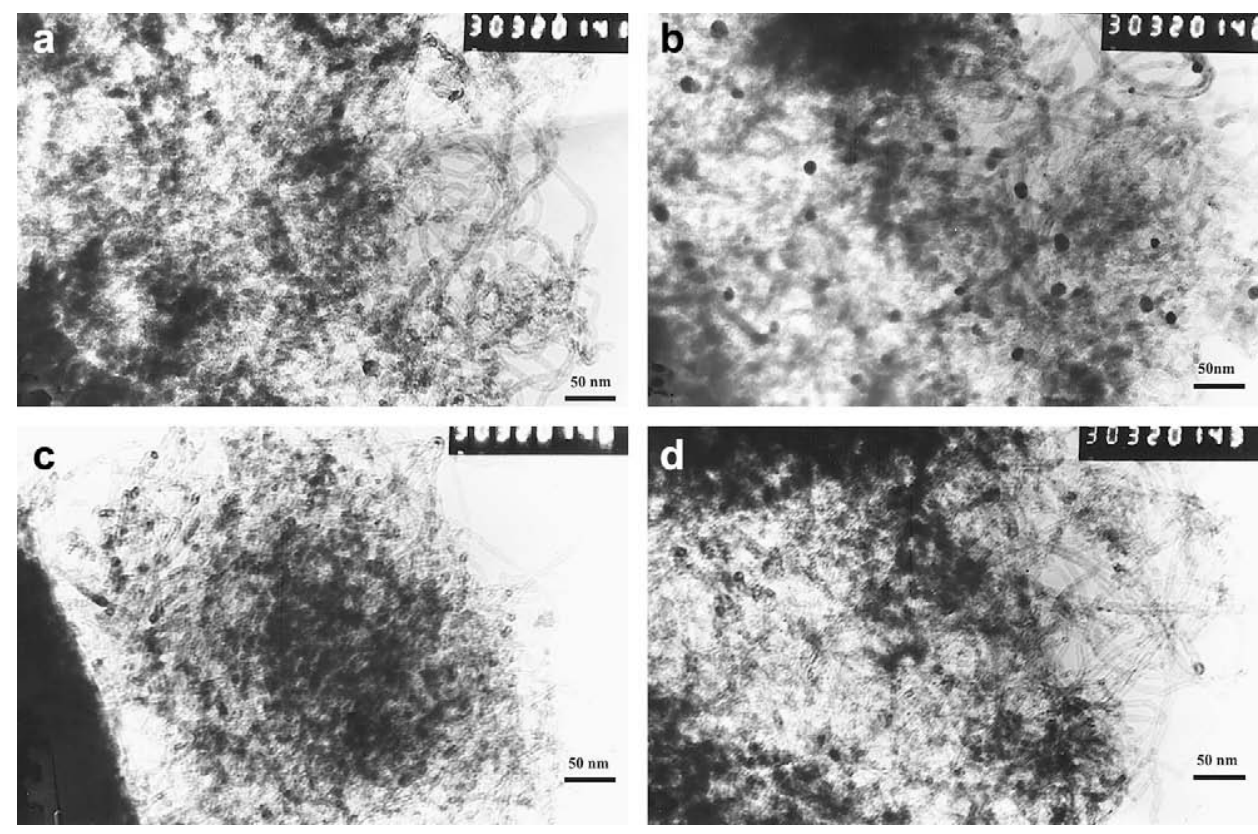

Fig. 2 - TEM images of the studied electrocatalysts. a) Sample 1, b) sample 2, c) sample 3 and d) sample 4.

possess inner holes, so the inner (trans-particle) porosity of MWCNTs is considerably higher. As can be seen, MWCNTs with thickness of 8-10 nm (see Fig. 2), stick on each other and their thickness increases to nearly $100 \mathrm{~nm}$.

FTIR analysis was performed in order to determine hypohyper d-interaction between the metallic phases and $\mathrm{TiO}_{2}$. In hypo-hyper d-interaction d-bonds are predominant. From the fact that $d$-bonding is responsible for adsorption/desorption processes $[34,35]$ which are an important part of the hydrogen evolution reaction, it is clear that the higher level of interaction means higher activity of the material for hydrogen evolution. FTIR spectra of the studied catalysts are shown in Fig. 4. The only band of interest originates from $\mathrm{TiO}_{2}$. To determine hypo-hyper d-interaction one has to compare $\mathrm{TiO}_{2}$ band from the electrocatalyst and a band from pure $\mathrm{TiO}_{2}$ obtained at identical conditions. The maximum of the pure $\mathrm{TiO}_{2}$ band is about $495 \mathrm{~cm}^{-1}$. The higher the shift of wave number, the shorter the bond between $\mathrm{TiO}_{2}$ and hyper dmetallic phase, i.e. the higher the hypo-hyper d-interaction. This shift is about $470 \mathrm{~cm}^{-1}$ for all samples (maximum of $\mathrm{TiO}_{2}$ band is at $965 \mathrm{~cm}^{-1}$ ) which evidences a considerable high hypo-hyper d-interaction. As a result of this an improved intrinsic activity for all electrocatalysts related to the corresponding pure metallic phases without $\mathrm{TiO}_{2}$ was observed. But because the value of the hypo-hyper $d$-interaction is the same for all catalysts under study, the expected differences in their electrocatalytic activity cannot be attributed to the increase of the intrinsic activity.

\subsection{Electrocatalytic activity for hydrogen evolution in the alkaline electrolyser}

In Fig. 5 are shown polarisation characteristics of the studied electrocatalysts for hydrogen evolution reaction in alkaline electrolyte. For comparison, a polarisation curve of pure Pt electrocatalyst deposited on Vulcan XC-72 using the same procedure is shown. The overpotentials for hydrogen evolution at referent current density of $60 \mathrm{~mA} \mathrm{~cm}^{-2}$ are shown in Table 2. The activity of the Co-based hypo-hyper d-electrocatalyst (sample 1) is very close to that of the traditional Pt/ Vulcan XC-72 one. This considerable improvement of catalytic activity of the Co-based catalyst is a result of several factors: i) intrinsic hypo-hyper d-interaction between $\mathrm{Co}$ and $\mathrm{TiO}_{2}$; ii) use of activated MWCNTs as carbon substrate, improving the inter- and trans-particle porosity as well as dispersion of the active catalytic centres over the catalytic surface; and iii) very small particles of Co (about $2 \mathrm{~nm}$ ), i.e. very high developed surface area of the metallic phase as the main catalytic centres.

These factors also explain why Pt-containing catalyst of this series (sample 4) is so superior to the traditional Pt catalyst. It has shown nearly $90 \mathrm{mV}$ lower overpotential for hydrogen evolution related to Pt/Vulcan XC-72. As shown in our previous works, the corresponding difference in overpotentials of the Co-based systems (Co/Vulcan XC-72 vs. Co/ $\mathrm{TiO}_{2} / \mathrm{MWCNTs}$ ) is about $130 \mathrm{mV}$ [21], while for Ni-based catalysts (Ni/Vulcan XC-72 vs. Ni/TiO $/$ MWCNTs) it is even $250 \mathrm{mV}$ [20].

The best catalytic activity is shown by the catalysts with mixed metallic phase Co:Pt $=1: 1$, wt. ratio. (sample 3), while the catalyst with mixed metallic phase $\mathrm{Co}: \mathrm{Pt}=4: 1$, wt. ratio (sample 2) is less active but still very close to the activity of pure Pt-based catalyst (sample 4). At the first glance, it is a paradox that the catalyst with double the amount of $\mathrm{Pt}$ (sample 4) is less active. But, there is logical explanation for this order of catalytic activity. Let's consider the above factors having an influence on the catalytic activity. The intrinsic hypo-hyper d-interaction is the same in all catalysts. They all have better porosity and dispersion of the metallic phase as a result of MWCNT usage as catalyst support as well. Thus, the 

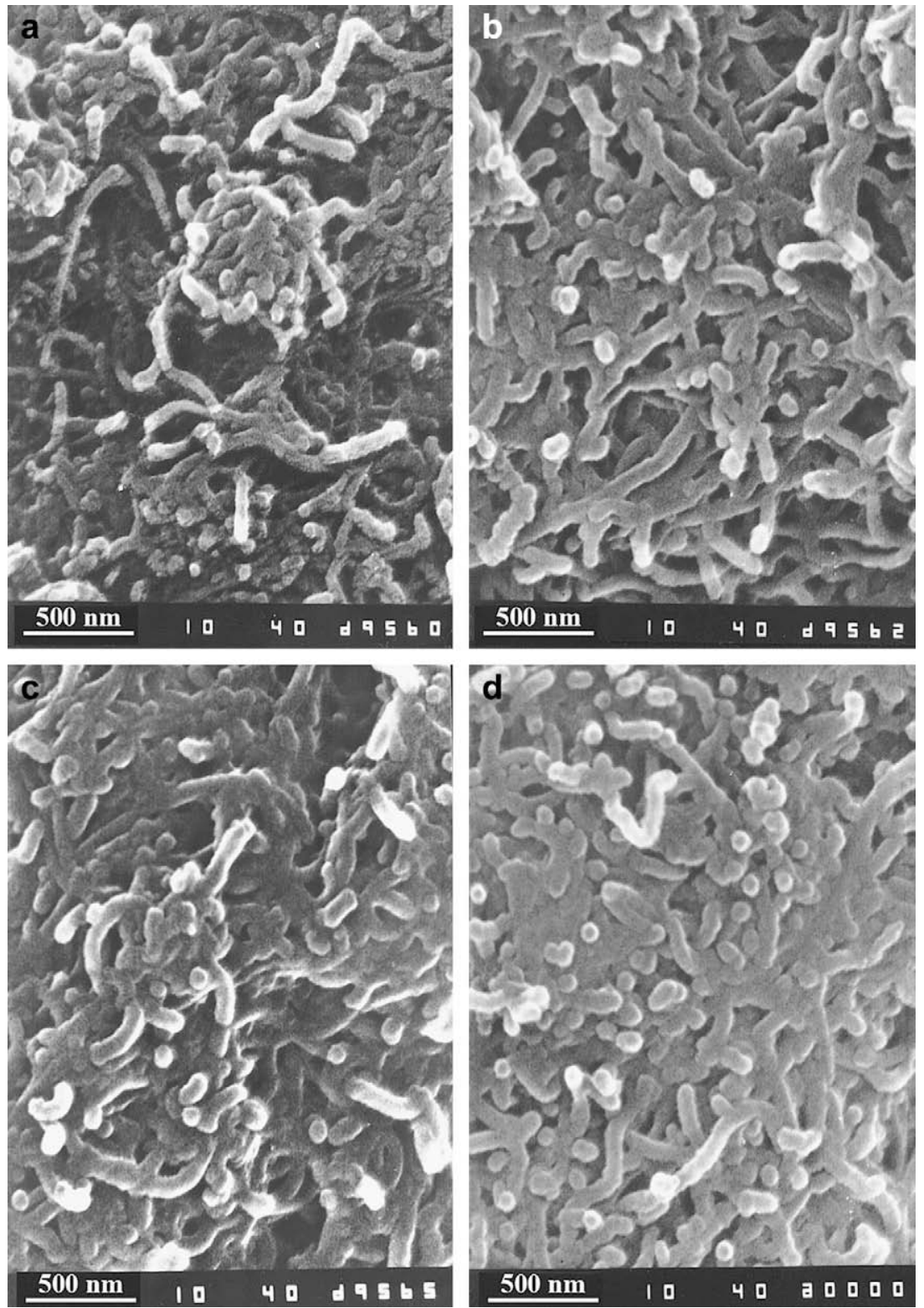

Fig. 3 - SEM images of the studied electrocatalysts. a) Sample 1, b) sample 2, c) sample 3 and d) sample 4.

improved activity of the catalyst with less amount of platinum obviously is related to the considerably lower size of Pt crystallites in the mixed systems. As it was shown from the XRD analysis, the size of Pt crystallites in sample 4 is about $12 \mathrm{~nm}$, while in the mixed systems (samples 2 and 3), Co promotes considerably lower (up to 3-4 times) size of Pt particles. The lower amount of Pt is compensated by the highly developed surface of Pt-phase in the mixed systems.

\subsection{Electrocatalytic activity for hydrogen evolution in the EasyTest Cell}

A series of quasi-steady-state cathodic polarisation curves of the studied catalysts and the commercially available ELAT were obtained in the EasyTest Cell. A detailed description of this electrochemical test approach and cell has been published elsewhere [25]. The experiments were carried out at a total pressure of $1.25 \times 10^{5} \mathrm{~Pa}$, temperature of $80^{\circ} \mathrm{C}$ with $100 \% \mathrm{RH}$, hydrogen partial pressure of $7.75 \times 10^{4} \mathrm{~Pa}$ and potential scan rate of $0.2 \mathrm{mV} \mathrm{s}^{-1}$. As it can be seen from the curves obtained on freshly prepared MEAs (Fig. 6) at current densities below $0.2 \mathrm{~A} \mathrm{~cm}^{-2}$ the best electrode performance, identical to that of ELAT is shown by the electrode containing catalyst sample 3 (Co:Pt $=1: 1$, wt. ratio), while the partial or complete substitution of Pt by Co in sample 2 and sample 1 leads to voltage penalties.

All of the tested electrodes have shown a stable electrode performance during a $24 \mathrm{~h}$ galvanostatic test at current density of $0.3 \mathrm{~A} \mathrm{~cm}^{-2}$ (Fig. 7). The electrode polarisations at $0.3 \mathrm{~A} \mathrm{~cm}^{-2}$ taken before and after the galvanostatic test are summarized in Table 3. While the trend in the electrode performance is similar to that obtained during the short-term 


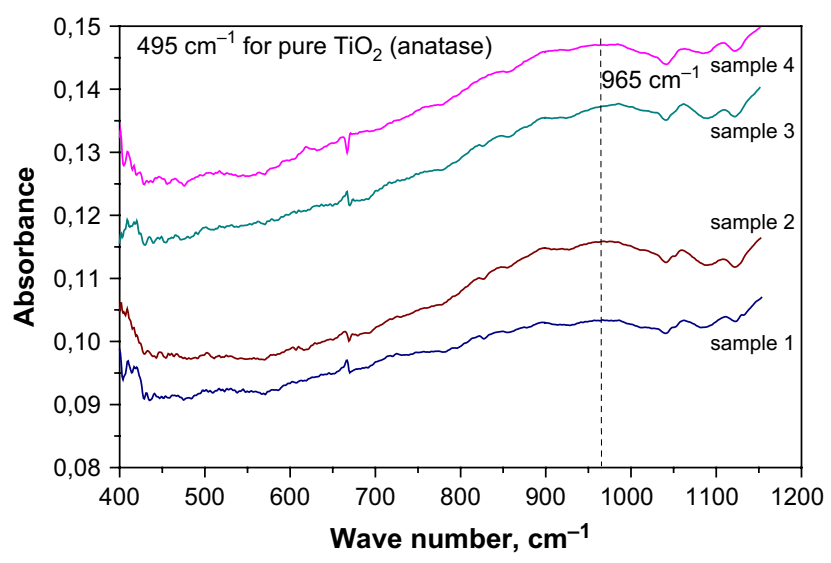

Fig. 4 - Infrared spectra of $\mathrm{TiO}_{2}$ originated from the studied electrocatalysts.

tests, higher voltage penalties of ca. 100 and $50 \mathrm{mV}$, were observed for the electrodes containing catalysts with mixed metallic phase (sample 3 and sample 2, respectively). On the contrary, the pure Co-based electrode enhanced its perfor-

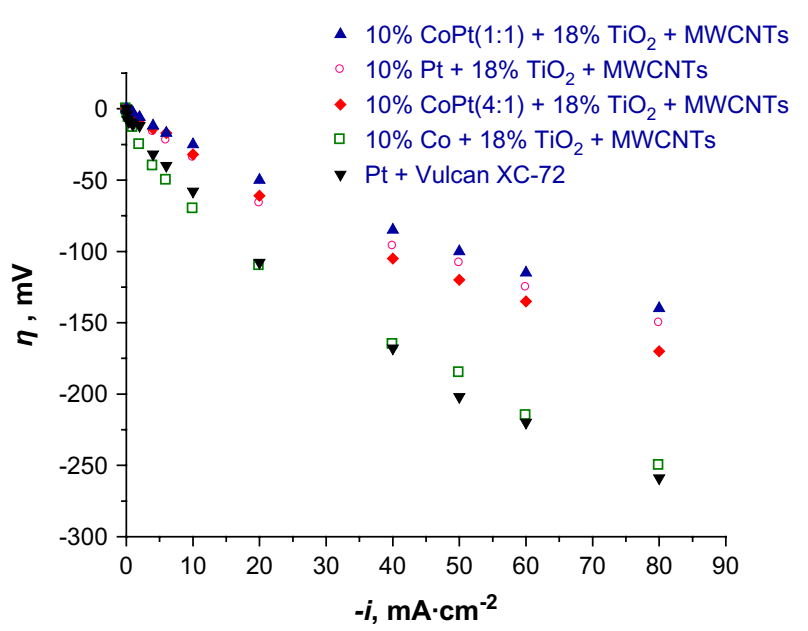

Fig. 5 - Steady-state polarisation curves of investigated electrocatalysts in alkaline cell.

mance gaining a decrease of $65 \mathrm{mV}$ in the electrode polarisation.

In order to obtain information about the influence of the studied catalysts (as hydrogen evolution electrodes) on the

Table 2 - Overpotentials at $60 \mathrm{~mA} \mathrm{~cm}{ }^{-2}$ for hydrogen evolution reaction of the studied electrocatalysts.

\begin{tabular}{lc} 
Sample no. (see Table 1) & $\eta_{60} / \mathrm{mV}$ \\
\hline 1 & -215 \\
2 & -135 \\
3 & -115 \\
4 & -125 \\
5 & -220 \\
\hline
\end{tabular}

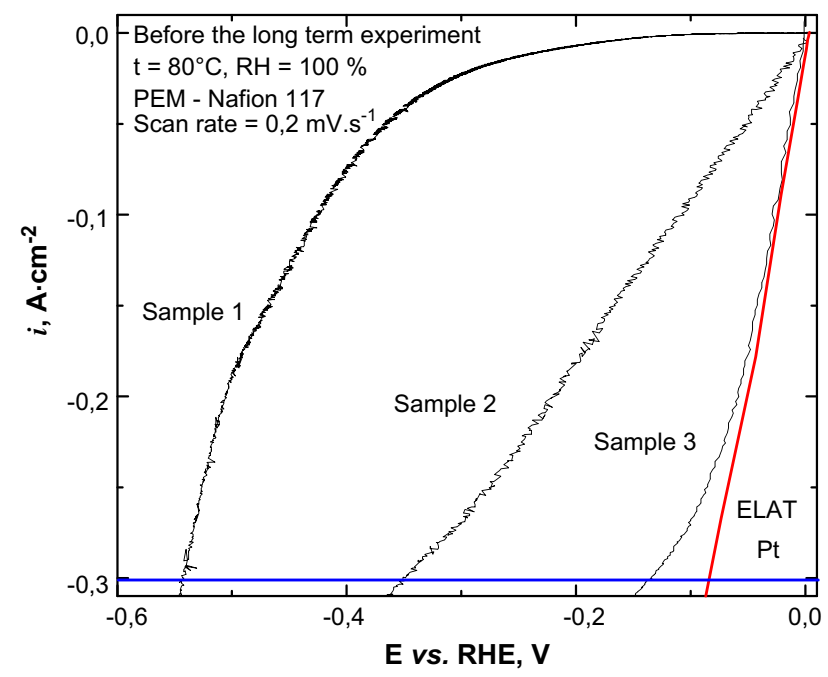

Fig. 6 - Quasi-steady-state polarisation curves of the investigated electrocatalysts as cathode for hydrogen evolution in MEAs in EasyTest Cell, using Nafion 117 proton exchange membrane.

cell performance of a single cell PEM water electrolyser the above data were combined with previous ETC results for oxygen evolution on $\mathrm{IrO}_{x}$ electrode [36,37]. The measured anode polarisation on the $\mathrm{IrO}_{x}$ electrode at current density of $0.3 \mathrm{~A} \mathrm{~cm}^{-2}$ was $1.6 \mathrm{~V}[36,37]$. In Table 4 are presented the calculated cell potentials and the corresponding cell efficiency values as ratio of the theoretical and determined cell voltages at $0.3 \mathrm{~A} \mathrm{~cm}^{-2}$. Sample 3 has shown the best cell efficiency, only $5 \%$ lower than that of commercial Pt. The poorest efficiency, $13 \%$ lower related to commercial $\mathrm{Pt}$, has been shown by sample 1. Taking into consideration the fact that this sample contains only Co as metallic phase $(0 \% \mathrm{Pt})$, such efficiency can be considered as very satisfying.

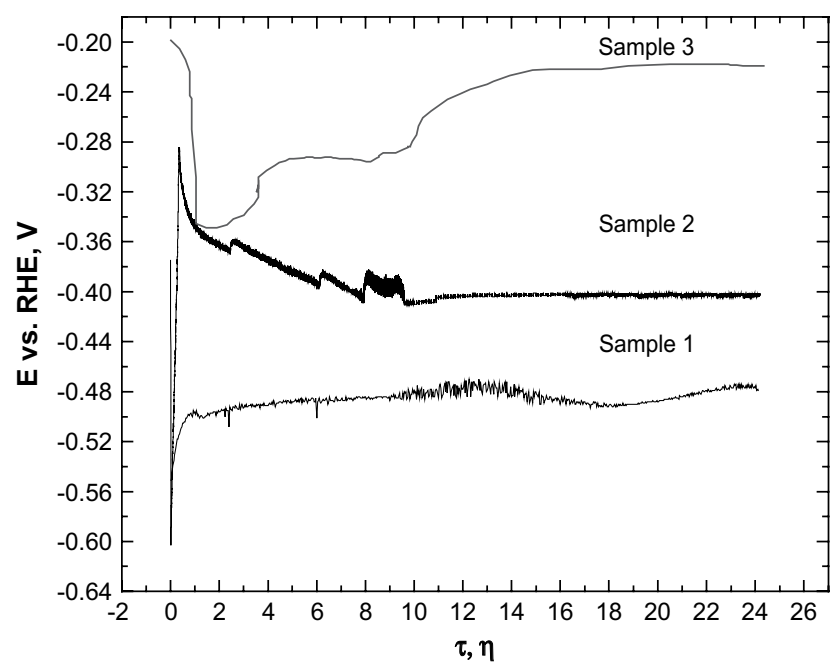

Fig. 7 - Long-term galvanostatic test of the studied electrode materials in EasyTest Cell at $0.3 \mathrm{~A} \mathrm{~cm}^{-2}$ for $24 \mathrm{~h}$. 
Table 3 - Electrode potentials $(E)$ registered before and after long-term electrode performances.

\begin{tabular}{|c|c|c|}
\hline \multirow{2}{*}{$\begin{array}{l}\text { Electrode } \\
\text { prepared } \\
\text { of the sample } \\
\text { no. }\end{array}$} & \multicolumn{2}{|c|}{$E$ vs. RHE, $\mathrm{mV}$ at $i=0.3 \mathrm{~A} \mathrm{~cm}^{-2}$} \\
\hline & $\begin{array}{l}\text { Defore long-term } \\
\text { experiment }\end{array}$ & $\begin{array}{l}\text { After long-term } \\
\text { experiment }\end{array}$ \\
\hline ELAT (E-TEK) & -83 & - \\
\hline 3 & -133 & -220 \\
\hline 2 & -350 & -402 \\
\hline 1 & -543 & -478 \\
\hline
\end{tabular}

Table 4 - Cell voltage and efficiency of PEM water electrolyser (studied electrocatalysts as cathode and $\mathrm{IrO}_{\mathrm{x}}$ as anode) calculated at $\mathrm{i}=0.3 \mathrm{~A} \mathrm{~cm}^{-2}$ (Nafion $117,80^{\circ} \mathrm{C}$, $\mathbf{R H}=\mathbf{1 0 0} \%$ ).

\begin{tabular}{lcc}
$\begin{array}{l}\text { Electrode prepared } \\
\text { of the sample no. }\end{array}$ & Cell voltage, $\mathrm{mV}$ & Efficiency, \% \\
\hline ELAT (E-TEK) & 1683 & 70.4 \\
3 & 1820 & 65.1 \\
2 & 2002 & 59.1 \\
1 & 2078 & 57.0 \\
\hline
\end{tabular}

\section{Conclusions}

The investigations presented in this paper were motivated by the idea to reduce or even replace Pt in self-developed electrode material for hydrogen evolution. Electrocatalysts with pure metallic phase (Co and $\mathrm{Pt}$ ) and mixed metallic phase (CoPt, 4:1 and 1:1, wt. ratio) deposited on catalyst support consisting of $\mathrm{TiO}_{2}$ and activated MWCNTs were prepared and studied. According to the achieved results the following conclusions can be drawn:

1. The addition of Co-acac during the sol-gel synthesis results in the decrease in the size of the Pt particles from 12 to 3$4 \mathrm{~nm}$ (XRD, TEM). Thus, Co has shown to be a promoter reducing considerably the size of the Pt crystallites.

2. As a result of the Pt particle size reduction, the surface area of the metallic phase increases, that compensates the less amount of Pt in the catalytic activity. The activity of the catalyst with only $20 \mathrm{wt} . \% \mathrm{Pt}$ in metallic phase is close to that of pure Pt-containing catalyst, while the catalyst with $50 \% \mathrm{Pt}$ in metallic phase exceeds its activity. It should be mentioned that improvement of the catalytic activity is a result of the rise of both hypo-hyper d-interaction and real surface area. Because the level of hypo-hyper d-interaction in all studied catalysts is almost the same, differences in catalytic activity are a result of corresponding differences of the 'size effect'.

3. The improved activity of all hypo-hyper d-Pt-containing catalysts deposited on activated MWCNTs compared to the traditional Pt/Vulcan XC-72 is a result of: i) intrinsic hypohyper d-interaction between hyper d-metallic phase and $\mathrm{TiO}_{2}$, and ii) improved inter- and trans-particle porosity as well as dispersion of the active catalytic centres over the catalytic surface.
4. In comparison to the commercial Pt electrode (ELAT) in the PEM electrochemical cell, the efficiency penalty of the water electrolysis based on the best electrode of the studied series (catalyst with metallic phase CoPt, 1:1 wt. ratio, sample 3 ) is about $5 \%$.

5. The complete substitution of Pt by Co in the hydrogen electrode (sample 1) results in efficiency penalty of ca. 13\% compared to the commercial Pt electrode (ELAT).

The investigated catalytic systems are rather complex and one could practically never state that the best of their performance is achieved. Further modification of both the catalyst's components and preparation of the MEA can contribute to increase even more the catalytic activity for HER and eventually, to replace Pt completely in the electrode materials.

\section{Acknowledgement}

This study was supported by and carried out within the Bilateral Project of the Ministry of Education and Science of Macedonia and Bulgarian Ministry of Education and Science (Contract No. BM-10/06).

Special gratitude is due to Prof. Milan Jakšić, University of Belgrade, for his bountiful and extensive help in the literature supply and valuable advices for both theoretical consideration and practical aspects of catalyst preparation.

I. Radev would like to thank Altrnative Energy Sources (ALENES) Project BG051P0001/07/3.3-02/17.06.

Thanks to Djordji Petruševski for his help in FTIR measurement and analysis.

\section{R E F E R E N C E S}

[1] Staschewski D. Internal humidifying of PEM fuel cells. Int J Hydrogen Energy 1996;21(5):381-5.

[2] Kim CS, Chun YG, Peck DH, Shin DR. A novel process to fabricate membrane electrode assemblies for proton exchange membrane fuel cells. Int J Hydrogen Energy 1998; 23(11):1045-8.

[3] Budevski E. Structural aspects of fuel cell electrodes. J Optoelectron Adv Mater 2003;5(5):1319-25.

[4] Yoon YG, Park GG, Yang TH, Han JN, Lee WY, Kim CS. Effect of pore structure of catalyst layer in a PEMFC on its performance. Int J Hydrogen Energy 2003;28(6):657-62.

[5] Smirnova A, Dong X, Hara H, Vasiliev A, Sammes N. Novel carbon aerogel-supported catalysts for PEM fuel cell application. Int J Hydrogen Energy 2005;30(2):149-58.

[6] Kim KH, Kim HJ, Lee KY, Jang JH, Lee SY, Cho E, et al. Effect of Nafion ${ }^{\circledR}$ gradient in dual catalyst layer on proton exchange membrane fuel cell performance. Int J Hydrogen Energy 2008; 33(11):2783-9.

[7] Chen J, Matsuura T, Hori M. Novel gas diffusion layer with water management function for PEMFC. J Power Sources 2004;131:155-61.

[8] Prasanna M, Cho EA, Kim HJ, Oh IH, Lim TH, Hong SA. Performance of proton-exchange membrane fuel cells using the catalyst-gradient electrode technique. J Power Sources 2007;166:53-8. 
[9] Hwnag JJ, Chang WR, Peng RG, Chen PY, Su A. Experimental and numerical studies of local current mapping on a PEM fuel cell. Int J Hydrogen Energy 2008;33(20):5718-27.

[10] US Department of Energy (DOE FY). Annual progress report; $2002 \& 2004$.

[11] Lee K, Zhang J, Wang H, Wilinson DP. Progress in the synthesis of carbon nanotube- and nanofiber-supported Pt electrocatalysts for PEM fuel cell catalysis. J Appl Electrochem 2006;36:507-22.

[12] Sato N. Environmental science and energy technologies of automotive engineering in the 21st century. Oyo Buturi 2003; 72(7):857-64.

[13] Arita M. Technical issues of fuel cell systems for automotive application. Fuel Cells 2002;2(1):10-4.

[14] Jakšić MM. Advances in electrocatalysis for hydrogen evolution in the light of the Brewer-Engel valence-bond theory. Int J Hydrogen Energy 1987;12(11):727-52.

[15] Jakšić MM. Volcano plots along the periodic table, their causes and consequences on electrocatalysis for hydrogen electrode reaction. J New Mater Electrochem Systems 2000;3:153-68.

[16] Neophytides SG, Zaferiatos SH, Jakšić MM. Novel trends in electrocatalysis: extended Brewer hypo-hyper-d-interionic bonding theory and selective interactive grafting of composite bifunctional electrocatalysis for simultaneous anodic hydrogen and CO oxidation. Chem Ind Chem Eng Q 2003;9(3):368-92.

[17] Serp P, Corrias M, Kalck P. Carbon nanotubes and nanofibers in catalysis. Appl Catal A Gen 2003;253:337-58.

[18] Sahaym U, Norton MG. Advances in the application of nanotechnology in enabling a 'hydrogen economy'. J Mater Sci 2008;43:5395-429.

[19] Yu X, Ye S. Recent advances in activity and durability enhancement of $\mathrm{Pt} / \mathrm{C}$ catalytic cathode in PEMFC part I. Physico-chemical and electronic interaction between Pt and carbon support, and activity enhancement of Pt/C catalyst. J. Power Sources 2007;172:133-44.

[20] Paunović P, Popovski O, Dimitrov AT, Slavkov D, Lefterova E, Hadži Jordanov S. Improvement of performances of complex non-platinum electrode materials for hydrogen evolution. Electrochim Acta 2006;52:1810-7.

[21] Paunović P, Popovski O, Dimitrov AT, Slavkov D, Lefterova E, Hadži Jordanov S. Study of structural and electrochemical characteristics of Co-based hypo-hyper delectrocatalysts for hydrogen evolution. Electrochim Acta 2007;52:4640-8.

[22] Paunović P, Dimitrov AT, Popovski O, Slavkov D, Hadži Jordanov S. Use of multiwalled carbon nanotubes (MWCNTs) as a support material in complex electrocatalysts for hydrogen evolution. Maced J Chem Chem Eng 2007;26(2):87-93.
[23] Paunović P, Dimitrov AT, Popovski O, Lefterova E, Grozdanov A, Petruševski Đ, et al. Effect of purification of multiwalled carbon nanotubes (MWCNTS) on electrocatalytic activity of catalysts for hydrogen evolution

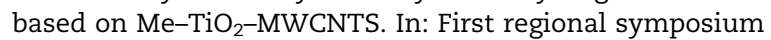
on electrochemistry of south-east Europe, Rovinj, Croatia; May 4-8 2008. p. 130.

[24] Paunović P, Popovski O, Radev I. Investigation of cell assemblies prepared out of electrocatalysts aimed for hydrogen evolution. Bull Chem Technol Macedonia 2005; 24(2):133-41.

[25] Radev I, Slavcheva E, Budevski E, Schnakenberg U. Simulations and study of electrochemical hydrogen energy conversion in EasyTest Cell. Electrochim Acta 2008; doi:10.1016/j.electacta.2008.09.006.

[26] BG patent appl. no 38581, 1978.

[27] Cullity BD. Elements of X-ray diffraction. London: Addison-Wesley Publishing Company Inc; 1978. p. 99.

[28] JCPDS - International Centre for Diffraction Data PDF-2 no. 89-4921, 2002.

[29] JCPDS - International Centre for Diffraction Data PDF-2 no. 89-4307, 2002.

[30] JCPDS - International Centre for Diffraction Data PDF-2 no. 87-0646, 2002.

[31] Lima FHB, Lizcano-Valbuena WH, Teixeira-Neto E, Nart FC, Gonzalez ER, Ticianelli EA. Pt-Co/C nanoparticles as electrocatalysts for oxygen reduction in $\mathrm{H}_{2} \mathrm{SO}_{4}$ and $\mathrm{H}_{2} \mathrm{SO}_{4} /$ $\mathrm{CH}_{3} \mathrm{OH}$ electrolytes. Electrochim Acta 2006;52:385-93.

[32] Slavcheva E, Nikolova V, Petkova T, Lefterova E, Vitanov T, Budevski E. On the role of Magneli phase $\mathrm{Ti}_{n} \mathrm{O}_{2 n-1}$ support in the electrocatalytic activity of Pt and CoPt synthesized by $\mathrm{BH}$ reduction. In: 55th annual meeting of the International Society of Electrochemistry, Electrochemistry: from Nanostructures to Power Plant, book of abstracts II. Thessaloniki, Greece; September 19-24 2004. p. 716.

[33] Antolini E, Salgado JRC, Giz MJ, Gonzalez ER. Effects of geometric and electronic factors on ORR activity of carbon supported Pt-Co electrocatalysts in PEM fuel cells. Int J Hydrogen Energy 2005;30(11):1213-20.

[34] Brewer L. Bonding and structures of transition metals. Science 1968;161:115-22.

[35] Jakšić MM. Brewer intermetallic phases as synergetic electrocatalysts for hydrogen evolution. Mater Chem Phys 1989;22:1-26.

[36] Slavcheva E, Radev I, Bliznakov S, Topalov G, Andreev P, Budevski E. Sputtered iridium oxide films as electrocatalysts for water splitting via PEM electrolysis. Electrochim Acta 2007;52:3889-94.

[37] Slavcheva E, Radev I, Topalov G, Budevski E. Sputtered electrocatalysts for PEM electrochemical energy converters. Electrochim Acta 2007;53:362-8. 